\title{
Edge-Strengthening of Structural Glass with Protective Coatings
}

\author{
M. Lindqvist ${ }^{1,}$ a, C. Louter ${ }^{1, b}$, J.-P. Lebet ${ }^{1, c}$ \\ ${ }^{1}$ Steel Structures Laboratory ICOM, ÉCOLE POLYTECHNIQUE FÉDÉRALE DE LAUSANNE \\ (EPFL) School of Architecture, Civil and Environmental Engineering (ENAC), Lausanne, \\ Switzerland \\ a maria.lindqvist@epfl.ch, ${ }^{\mathrm{b}}$ christian.louter@epfl.ch, \\ `jean-paul.lebet@epfl.ch
}

Keywords: Glass, coatings, edge strength, mechanical properties

Abstract. In modern buildings, glass is increasingly used as a load-carrying material in structural components, such as glass beams. For glass beams especially the edge strength of glass is important. However, the strength of glass is not a material constant but depends on various parameters, which makes glass, amongst other things, a challenging building material. One of the parameters influencing glass strength is the combination of humidity and stress, which may cause stress corrosion.

The aim of the current study is to limit the effect of humidity at the glass edge. This is done by the application of a protective coating. In this exploratory study several coating solutions are tested applying the coating at the edge of glass specimens. These specimens are then subjected to in-plane four-point bending tests to determine their failure strength. The effects of the coatings on the edge strength are analyzed using the failure strength data from the bending tests. The results indicate that only one of the tested coatings has an effect on the glass edge strength.

\section{Introduction}

In this study, the use of coatings in structural glass applications is investigated. Similar to Wen [1], the current study focuses on strengthening the glass edge. Earlier publications on the strengthening effects of glass coatings have been reported by several sources, using acrylate coatings [1], epoxy coatings [2] and silicon grease [3]. These authors attribute the strengthening effect of these coatings to their ability to protect the glass against stress corrosion.

\section{Materials}

Small-scale soda-lime silicate glass specimens were used, and the edge strength was investigated with and without a coating. All glass specimens were cut from polished glass panes and the polished edge was loaded in four-point bending tests. The nominal dimensions of the specimens were $110 \times 10 \times 4 \mathrm{~mm}$ with a support-span of $100 \mathrm{~mm}$, and load-span of $50 \mathrm{~mm}$.

Several coating solutions were tested:

1. Bioresin Biovest 578

2. Bluestar Silicones BP 9710

3. Rhodorsil Silicon grease Paste 4

4. Epoxy resin, Dow (DER 330, DER 732, DEH 26)

5. Tape, Gyso V712, Adhesive tape based on butyl rubber $(0.8 \mathrm{~mm})$ aluminum sheet coated with polyester.

\section{Preparation and testing}

Before testing, glass specimens were cleaned and heated up to 100 degrees in an oven for 48 hours. During heating, the specimens were covered with humidity absorbing molecular sieves (Zeochem, Z4-04) to absorb moisture. After cooling, the edges of the specimens were coated within a few seconds with one of the coatings listed above. Furthermore, the coatings dried following the instructions of each product specifications. 
Thereafter, the glass specimens were loaded in-plane using an Instron 5948 MicroTester machine. Two stress rates used were $19 \pm 2.5 \mathrm{MPa} / \mathrm{s}$ (high) and $0.14 \pm 0.02 \mathrm{MPa} / \mathrm{s}$ (low). Each series contained 20 specimens per one stress rate. Thus, the series of specimens without a coating had 40 specimens including 20 specimens for both stress rates.

\section{Test results}

The effect of the coatings on the edge strength was analyzed using the failure strength data from the bending tests. The analysis was made using the two-parameter Weibull distribution function [4]. The experimental failure strength values are presented in Table 1. In addition, the Weibull fit to the failure strength values is shown in Fig. 1.

Table 1: Failure strength data analyzed using the two-parameter Weibull distribution.

\begin{tabular}{|c|c|c|c|c|c|c|c|}
\hline Stress rate & $\begin{array}{l}0 \\
\text { Uncoated } \\
\text { high }\end{array}$ & $\begin{array}{l}0 \\
\text { Uncoated } \\
\text { low }\end{array}$ & $\begin{array}{l}1 \\
\text { Bioresin } \\
\text { Biovest } \\
578 \\
\text { low }\end{array}$ & $\begin{array}{l}2 \\
\text { Bluestar } \\
\text { Silicones } \\
\text { BP } 9710 \\
\text { low }\end{array}$ & $\begin{array}{l}3 \\
\text { Rhodorsil } \\
\text { Silicon } \\
\text { grease } \\
\text { low }\end{array}$ & $\begin{array}{l}4 \\
\text { Epoxy } \\
\text { resin } \\
\text { low }\end{array}$ & $\begin{array}{l}5 \\
\text { Tape } \\
\text { Gyso } \\
\text { V712 } \\
\text { low }\end{array}$ \\
\hline $\begin{array}{l}\text { Mean strength } \\
\hat{\boldsymbol{\mu}}[\mathrm{MPa}]\end{array}$ & 81.18 & 63.16 & 62.41 & 63.96 & 79.40 & 63.20 & 68.96 \\
\hline $\begin{array}{l}\text { Variation } \\
\text { coefficient } \widehat{\boldsymbol{V}} \\
{[\%]}\end{array}$ & 12.03 & 13.27 & 11.53 & 16.73 & 8.99 & 11.78 & 17.47 \\
\hline $\begin{array}{l}\text { Weibull scale } \\
\text { parameter } \widehat{\boldsymbol{\theta}} \\
{[\mathrm{MPa}]}\end{array}$ & 85.33 & 66.69 & 65.48 & 68.36 & 82.49 & 66.37 & 73.89 \\
\hline $\begin{array}{l}\text { Weibull shape } \\
\text { parameter } \widehat{\boldsymbol{\beta}}\end{array}$ & 10.00 & 9.02 & 10.46 & 7.03 & 13.59 & 10.22 & 6.71 \\
\hline
\end{tabular}

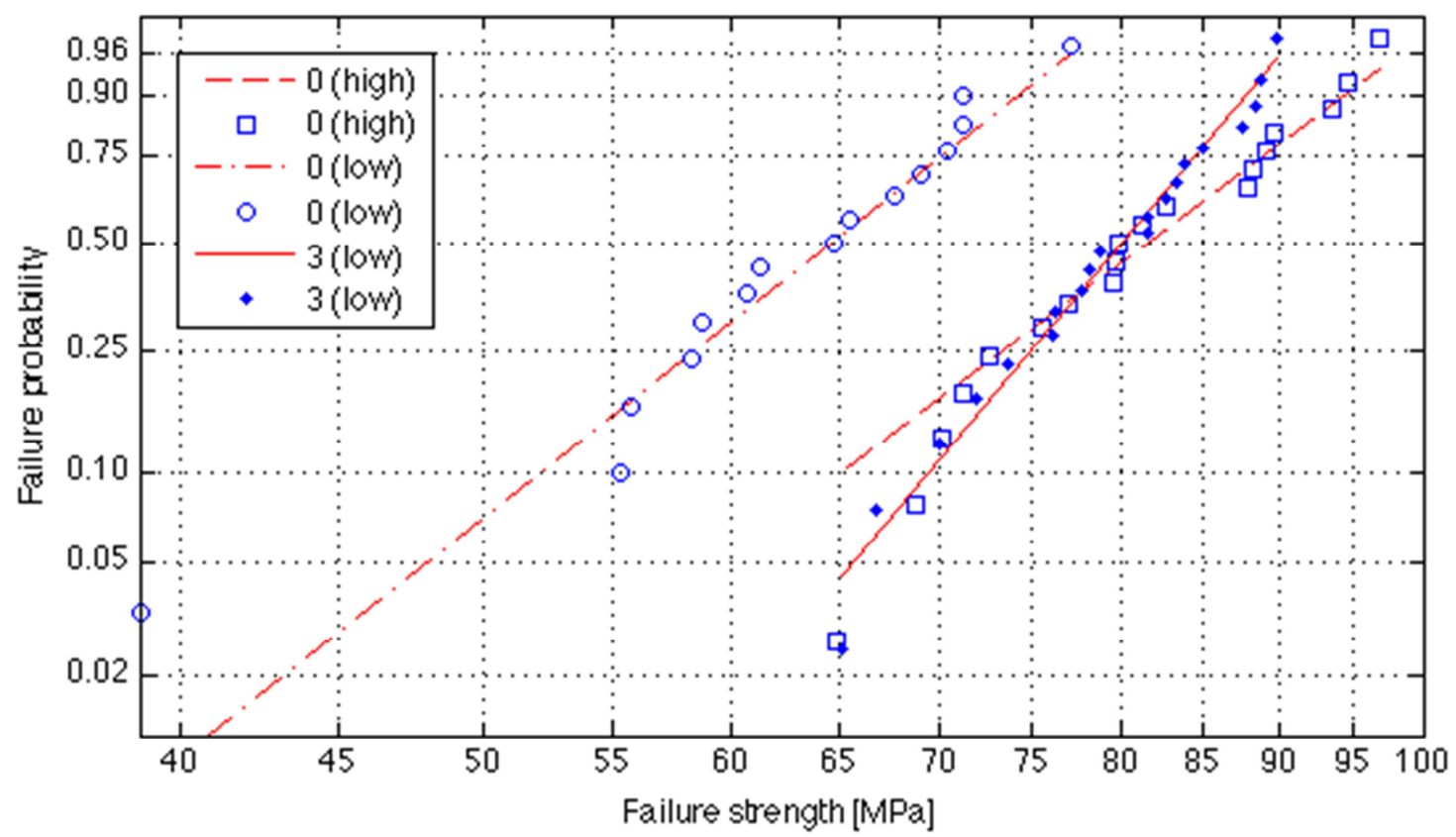

Fig. 1: The failure strength values (dots) with the Weibull distribution fitting (lines) for uncoated series $(0)$ at the high and low stress rates and the coating 3 values at the low stress rate. 
The thickness of the coatings was studied using a confocal microscope (LSM710). Fig. 2 a) and b) show an illustration of the glass cross-section after failure. The coating layer is situated on the glass edge. The study with the microscope showed that the thickness of the coatings varied between 20 $\mu \mathrm{m}$ and $200 \mu \mathrm{m}$ depending on the viscosity of the coating product.
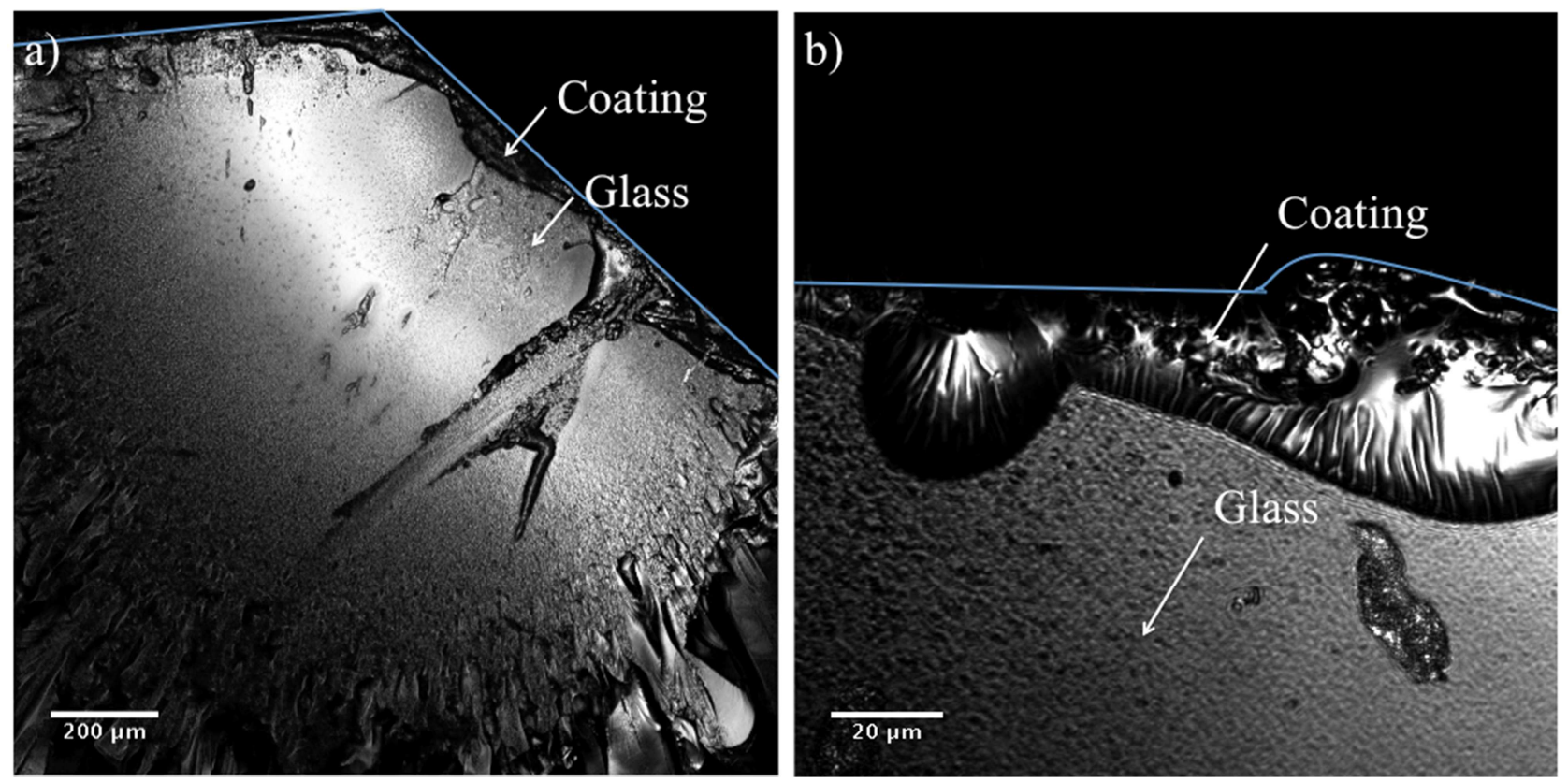

Fig. 2: a) An illustration of the glass edge at the failure location showing the layer of coating 3, Rhodorsil Silicon grease Paste 4, on top of the glass. The figure presents a part of the cross-section of the glass specimen as well as the location where a flaw initiates the failure. b) A layer of epoxy resin (coating 4) covering the glass edge-surface.

\section{Discussion}

Seven series of 20 specimens were tested in-plane in four-point bending. From the failure strength values the following is observed.

Firstly, the uncoated specimens loaded at a high stress rate reached higher average strength level than the uncoated specimens that were loaded at a low stress rate. The difference amounted to $22 \%$. The difference is assumed to be related to the effect of humidity on the glass strength and was expected according to [3].

Secondly, it is observed that the specimens with coatings 1,2 and 4 loaded at a low stress rate, reached similar strength levels as the uncoated specimens that were also loaded at low stress rate. From this it is observed that the coating 1,2 and 4 had no significant effect on the edge strength of the glass specimens.

Thirdly, the specimens coated with coating 3 loaded at a low stress rate, reached similar strength levels as the uncoated specimens that were loaded at a high stress rate. Here, the coating had a 'strengthening' effect on the glass.

Finally, it is observed that coating 5 had an inconsistent effect on the edge strength of the glass specimens. The specimens with coating 5 showed a tendency for increased strength. However, as can be seen from Table 1 the scatter in the results of the specimens with coating 5 is rather large.

\section{Conclusions}

In this study, the use of coatings at the glass edge for structural glass applications is investigated. The use of a protective coating is proposed to limit the effects of humidity at the glass edge. The results showed that only one coating, Rhodorsil Silicon grease Paste 4, managed to protect the edge during testing. Coating 5, Tape Gyso V-712, had a small influence.

The microscope detection of the glass surface with coatings allowed to estimate the thickness of the coatings. However, further study is required to estimate why only the coating 3 had an effect on the glass edge strength. 
The advantage of a protective coating is to decrease the scatter of strength levels, thus avoiding the dependency in stress rate. If this scatter in strength can be avoided by using a coating, such an improvement in strength would be significant in the design of structural glass.

In order to obtain more proof on the use of protective coatings, a future study is suggested on the details of the chemical and mechanical properties of coatings, their long-term effects, and the capability of coatings to protect the glass under changing environmental conditions. This includes a non-destructive evaluation on the micro level effects of coatings especially at the crack-tip area.

\section{Acknowledgements}

The study is made with the assistance of testing equipment provided by the Laboratory of Applied Mechanics and Reliability Analysis (LMAF) and the confocal microscope in BioImaging and Optics platform (PTBIOP) at EPFL. Also the financial support of Swiss National Science Foundation (SNSF) is acknowledged.

\section{References}

[1] M. Wen, J.-M. Chapagno, G. Silverman, M. Bourrel: submitted to Journal of Non-Crystalline Solids 354 (2008), p. 5060-5067.

[2] R.J. Hand, B. Ellis, B.R. Whittle, F.H Want: submitted to Journal of Non-Crystalline Solids 315 (2003), p. 276-287.

[3] M. Haldimann, Fracture strength of structural glass elements - Analytical and numerical modeling, testing and design. Thesis EPFL (2006).

[4] EN-12603:2002 Glass in building- Procedures for goodness of fit and confidence intervals for Weibull distributed glass strength data, European Committee for Standardization. 